\title{
PowerPlex Y23 System: A Fast, Sensitive and Reliable Y-STR Multiplex System for Forensic and Population Genetic Purpose \\ Toshi Jain ${ }^{1,2, \#, ~ P a n k a j ~ S h r i v a s t a v a ~}{ }^{1 \# *}$, Bansal DD ${ }^{1}$, Dash HR ${ }^{1}$ and Veena Ben Trivedi ${ }^{1}$
}

${ }^{1} D N A$ Fingerprinting Unit, State Forensic Science Laboratory, Sagar-470001 (MP), India

${ }^{2}$ School of Studies in Microbiology, Jiwaji University, Gwalior (MP), India

"Authors equal Contributed

\begin{abstract}
Y-STR genotyping is an excellent tool for the identification of male DNA masked by female DNA, particularly in sexual assault cases where, more often the male and female components cannot be separated completely. Resultant, the female component could exist prominently even in the male component after separation. When the "male DNA sample mixed with female DNA" undergoes PCR by using autosomal STR multiplex amplification process, the female DNA component is also amplified, mostly masking the male DNA. Recently launched Y-STR kit, PowerPlex Y23 (PP Y23) System is a 5-dye multiplex genotyping kit that analyzes 17 Y-STR loci, commonly available in other Y-STR multiplex kits (DYS19, DYS385a/b, DYS389I/II, DYS390, DYS391, DYS392, DYS393, DYS437, DYS438, DYS439, DYS448, DYS456, DYS458, DYS635, and Y-GATA-H4) along with that 6 new Y-STR loci (DYS481, DYS533, DYS549, DYS570, DYS576, and DYS643). The addition of 6 new markers has made the Y-STR analysis more discriminating. The purpose of the present study is to show the amplification of male DNA from a wide variety of forensic samples using half the manufacturer's recommended reaction volume. Also the present study validates the kit for its use in Forensic casework. The results demonstrate that the PPY23 System is a robust and sensitive multiplex system, capable of giving reliable and consistent amplification results from a wide variety of forensic casework samples. Even the presence of high concentration of commonly encountered inhibitors such as hematin (from Blood) and humic acid (from soil), male/female DNA mixtures and low amounts of DNA template (15.62 pg) could not hamper the process of amplification.
\end{abstract}

Keywords: Y chromosome; Y-STR; Forensic; DNA typing; Short tandem repeat (STR); PowerPlex Y 23

\section{Introduction}

Over the years forensic DNA typing has earned the credibility of forensic scientists. Different variants of DNA fragment analysis technology is being used for different purposes in forensics [1]. Autosomes and $\mathrm{X}$ chromosome (only in daughters) are inherited from both the parents after recombination, while Y chromosome is inherited paternally and mitochondrial DNA is inherited maternally. The inheritance pattern of these markers makes them suitable for establishing paternal and maternal lineage [1].

In routine forensic biological and serological examination of rape cases presence of semen and/or spermatozoa is detected, which cannot link the evidence to a particular suspect. Because of this fact DNA typing in sexual assault cases has proven to be a better solution. Sexual assault cases, that routinely consists of evidentiary stains that are a mixture of body fluids from the victim and suspect. Though differential analysis technique permits the separation of the male and female components of the mixed stains [2]. However, a complete separation is not always possible [3-7]. These limitations of the separation process, makes it challenging for the forensic experts to interpret the mixed DNA profiles, with two or more contributors. In many circumstances the PCR based amplification methods fail to amplify the minor (e.g. male) component of DNA mixtures as they have to face the opposition with the alleles from the major (e.g. female) component, which tends to get amplified first. One approach towards resolving this issue is to target male-specific polymorphisms on the non recombining portion of the Y chromosome (NRY). The NRY is strictly inherited paternally and, therefore, is the best material to trace the paternal lineage with the additional advantages of small effective population size, low mutation rate, sufficient markers and population-specific haplotype distribution $[8,9]$. With the availability of genotyping markers for the NRY region, Y-DNA typing has become one of the most indispensable techniques in
Forensic DNA typing, especially in sexual assault cases which bump into issues like unsuccessful separation of male and female cells. Complete separation of male and female cells in not feasible in aforementioned cases because of certain reasons like, age and/or quality of semen stains, azoospermic men, the presence of other body fluids from victim and suspect of different sex, and, two or more male semen donors. The ability to target polymorphisms on the NRY region and the recent availability of improved multiplex markers for NRY, has made it possible to analyse such samples that were previously difficult to interpret. To understand the demographic history of human populations, Y chromosome has been widely used in anthropology and population genetics as well [10]. Two classes of NRY markers, short tandem repeats (Y-STRs) and single nucleotide polymorphisms (Y-SNPs) are being used in the present scenario. The combination of alleles at multiple Y-STR loci, on a single Y chromosome defines a Y-STR haplotype, whereas the combination of alleles at multiple SNPs defines a NRY haplogroup [11]. The high geographic specificity of many NRY haplogroups $[8,12]$ aids forensic scientists in narrowing down the geographic location of the perpetrator (male) with the help of circumstantial evidence left at the crime scene. The forensic utility of Y-STRs is the result of their high levels of polymorphism in human populations [13], their small size in base pairs

${ }^{*}$ Corresponding author: Pankaj Shrivastava, DNA Fingerprinting Unit, State Forensic Science Laboratory, Sagar-470001 (MP), India, Tel: +91 9424371946 ; E-mail: pankaj.shrivastava@rediffmail.com; ecsdsjbp@gmail.com

Received April 12, 2016; Accepted April 28, 2016; Published April 30, 2016

Citation: Jain T, Shrivastava P, Bansal DD, Dash HR, Trivedi VB (2016) PowerPlex Y23 System: A Fast, Sensitive and Reliable Y-STR Multiplex System for Forensic and Population Genetic Purpose. J Mol Biomark Diagn 7: 281. doi:10.4172/21559929.1000281

Copyright: (c) 2016 Jain T, et al. This is an open-access article distributed under the terms of the Creative Commons Attribution License, which permits unrestricted use, distribution, and reproduction in any medium, provided the original author and source are credited. 
( 100-400 bp), and the ability to type multiple Y-STRs in a single PCR reaction $[14,15]$. Two decades ago, since the first case investigation by Y-STR markers [16-18], the application scenario of Y-STR continuously evolved in various aspects like the number of markers. The original 9-Y-STR set, named as the minimal haplotype, expanded in number with time to increase the discrimination power of the Y-chromosome test [19] (e.g. PPY12 (PowerPlex Y12, Promega Corp., USA), Yfiler [AmpFlSTR Yfiler kit, (Applied BioSystem/Life Technologies/ThermoAB/LT/Thermo)]). The PP Y23 system (Promega Corp., USA) is a newly developed multiplex kit that allows the simultaneous analysis of 23 Y-STR markers, incorporating six new markers in addition to the previous markers of the Yfiler kit. This new Y-STR panel was recently validated for forensic use and for concordance with the Yfiler [20-22]. Multiple utility of PP Y23 system is presented in Figure 1.

Though a few publications report validation of PP Y23 in last few years [20-22] for forensic purpose but this is the first study reporting the trial of kit on a wide variety and number of forensic samples with interesting findings along with the validation study and proving the utility of PP Y23 system in forensic DNA typing casework from India, a country with diverse population. All the validation experiments were performed using half reaction volume of the recommended protocol of the manufacturer and complete Y23 STR profile was detected without any drop-ins or drop-outs. This was confirmed further by full volume PCR of tested samples as well.

\section{The PP Y23 System}

The PP Y23 System allows co-amplification of the several loci recommended in the European Minimal Haplotype (DYS19, DYS385a/b, DYS389I/II, DYS390, DYS391, DYS392, and DYS393) $[16,23]$, the two additional loci recommended by SWGDAM (DYS438 and DYS439) [24], as well as twelve additional loci (DYS437, DYS448, DYS456, DYS458, DYS481, DYS533, DYS549, DYS570, DYS576, DYS635, DYS643, and Y-GATA-H4). Six of the additional loci are highly discriminating Y-STR loci (DYS481, DYS533, DYS549, DYS570, DYS576 and DYS643) [25-27]. The PP Y23 System is configured with the majority of the highly discriminating loci with smaller amplicon size. Due to smaller amplicon size even trace amounts of DNA can be amplified and the discrimination potential of partial profiles can be maximized [20]. The PP Y23 System provides all the necessary materials to amplify the Y-STR regions of human genomic DNA. It includes a hot-start DNA polymerase, and is compatible with the 3100-Avant Genetic Analyzers and Applied Biosystems 3130, 3130xl, 3500 and $3500 x L$ Genetic Analyzers. The PP Y23 System is a 5-dye system. The blue channel consists of the fluorescein labelled STR

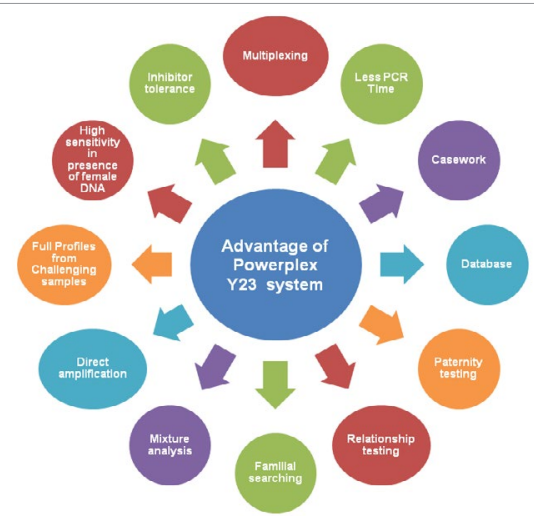

Figure 1: Features of PowerPlex Y23 System showing the diverse utility of PP Y23.

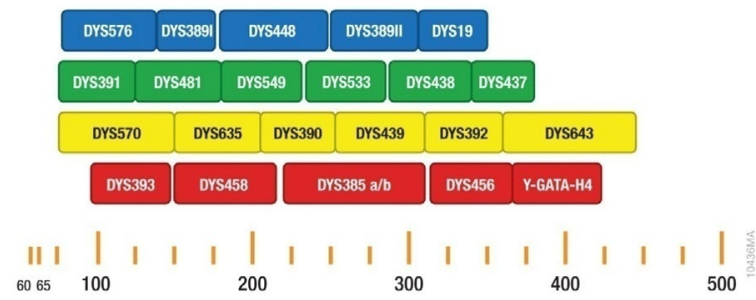

Figure 2: PowerPlex Y 23 system markers (Source- PowerPlex Y23 system manual).

amplicons for DYS576, DYS389I, DYS448, DYS389II, and DYS19. The green channel includes DNA fragments labelled with JOE for DYS391, DYS481, DYS549, DYS533, DYS438, and DYS437. The yellow channel consists of amplification products for DYS570, DYS635, DYS390, DYS439, DYS392, and DYS643 which are labelled with TMR-ET. The amplified products for DYS393, DYS458, DYS385a/b, DYS456 and Y-GATA-H4 are in the red channel and are labelled with CXR-ET. Fragments included in the internal lane standard are detected in the orange channel and are labelled with CC5 (CC5 Internal Lane Standard 500 Y23) (Figure 2).

\section{Materials and Methods}

\section{System sensitivity}

DNA samples organically extracted using automated DNA extraction system 12 GC (PSS, Matsudo, Japan) and quantified using real time PCR ABI 7500 (AB/LT/Thermo). Two male DNA samples were used for the sensitivity study. A serial dilution was performed with the following template amounts: $1000 \mathrm{pg}, 500 \mathrm{pg}, 250 \mathrm{pg}, 125 \mathrm{pg}, 62.5$ pg, $31.25 \mathrm{pg}$, and $15.62 \mathrm{pg}$ and $8.00 \mathrm{pg}$.

For the inhibition study, $1 \mathrm{ng}$ DNA sample mixed either with humic acid (final concentrations $10 \mathrm{ng} / \mu \mathrm{L}, 100 \mathrm{ng} / \mu \mathrm{L}, 200 \mathrm{ng} / \mu \mathrm{L}$ and $300 \mathrm{ng} /$ $\mu \mathrm{L}$ ) or hematin (final concentrations $20 \mu \mathrm{M}, 100 \mu \mathrm{M}, 200 \mu \mathrm{M}, 500 \mu \mathrm{M}$ and $700 \mu \mathrm{M}$ ) were used. The amplification performance of male:female (M:F) mixtures was tested using M:F mixture ratios. $1000 \mathrm{pg}$ of female DNA was mixed with varied quantity $(1000 \mathrm{pg}, 500 \mathrm{pg}, 250 \mathrm{pg}, 125$ pg, $62.5 \mathrm{pg}, 31.25 \mathrm{pg}, 15.62 \mathrm{pg}$ and $8.00 \mathrm{pg}$ ) of male DNA. For this, samples with a measured DNA concentration higher than $0.1 \mathrm{ng} / \mu \mathrm{L}$ were diluted with TE buffer to appropriate quantity. For accessing the direct Amplification compatibility, 1 and $0.5 \mu \mathrm{L}$ of saliva samples of 50 different males was amplified without any prior processing/treatment. In all the tested samples complete Y 23 STR profile was detected. No drop-ins or drop-outs were observed in all the tested samples, this was confirmed with the Y 23 profile of same samples amplified after DNA isolation. Direct amplification reactions were also performed using one $1.2 \mathrm{~mm}$ punches from FTA cards (having buccal/blood cells). Punches were added directly to the reaction mixture to check the direct amplification compatibility of FTA Cards (GE Healthcare/Whatman) with PP Y23 system. Amplification was performed by using half the manufacturer's recommended reaction volume.

\section{Casework and population data analysis for forensic and population genetic purpose}

PP Y23 system was tested with different variety of case work samples including clothing stained with different body fluids, tissues, vaginal smear slides, vaginal swabs, nail scrapings of females in case of sexual assault which might have male tissue struck in them, uterus where there was no discrimination with fetus (pregnancy of few weeks when there is no discrimination between mother and fetus) and swabs from the weapons etc. For forensic genetic analysis and comparison 
we used DNA from unrelated males from two tribal populations of the central India (Table 1). The PP Y23 system was also tested on brother's pairs and father son pairs to observe the patrilineal similarity between related individuals.

\section{DNA amplification}

All of the samples were amplified using GeneAmp PCR System 9700 thermal cycler (AB/LT/Thermo). The following amplification set-up and cycling parameters, as described in the PP Y23 Technical Manual (PP Y23 System Technical Manual, 7/12, available at: http:// www.promega.com/resources/protocols/technical-manuals/101/ powerplex-y23-system-protocol/, with the modification of using half the reaction volume of the recommended protocol. Each amplification reaction contained $2.5 \mu \mathrm{l}$ of PP Y23 Master Mix and $1.25 \mu \mathrm{l}$ of PP Y23 Primer Pair Mix, $0.5 \mu \mathrm{l}$ of DNA (200 pg) with up to $7.75 \mu \mathrm{l}$ of MQ water. Extracted DNA amplification reactions containing, $200 \mathrm{pg}$ of male DNA in a $12 \mu \mathrm{l}$ volume, were cycled as per the guidelines from the manufacturer. A 10 and $7 \mu \mathrm{l}$ reaction volume was also tested for amplification using PP Y23 System with $200 \mathrm{pg}$ and $100 \mathrm{pg}$ of male DNA. Samples used for direct amplification were processed using the same cycling parameters with the exception of the cycle number which was optimized for each substrate. Blood on FTA Cards was amplified with 26 cycles while buccal samples on FTA Cards were amplified with 28 cycles.

As the PP Y23 System employs five fluorescent dyes, spectral resolution was established using the PowerPlex 5-dye Matrix Standards (Promega Corporation) enabling evaluation of each fluorescent dye contained in the kit. A $36 \mathrm{~cm}$ capillary array was used with POP-4 Polymer (AB/LT/Thermo). Samples were prepared for separation and analysis by adding $1 \mu \mathrm{l}$ of amplified sample or allelic ladder to $10 \mu \mathrm{l}$ of Hi-Di Formamide (AB/LT/Thermo) and $0.5 \mu \mathrm{l}$ of ILS provided with PP Y23 system. Samples were denatured for $3 \mathrm{~min}$ at $95^{\circ} \mathrm{C}$ followed by a snap cool in an ice bath. All analyses used the CC5 Internal Lane Standard 500 Y23 (ILS) and the allelic ladder mix provided with the PP Y23 System. Separation of amplified products was performed on

\begin{tabular}{|c|c|c|c|}
\hline SI. No. & YHRD Accession no. & Haplotype count & Population \\
\hline 1 & YA004145 $^{*}$ & 107 & Chattisgarh, India (Majhi) \\
\hline 2 & YA004144 $^{*}$ & 217 & Madhya Pradesh, India (Bhil) \\
\hline
\end{tabular}

"data can be accessed from www.yhrd.org

Table 1: Population data analysis of two tribal population of central India by using PP Y23 system.

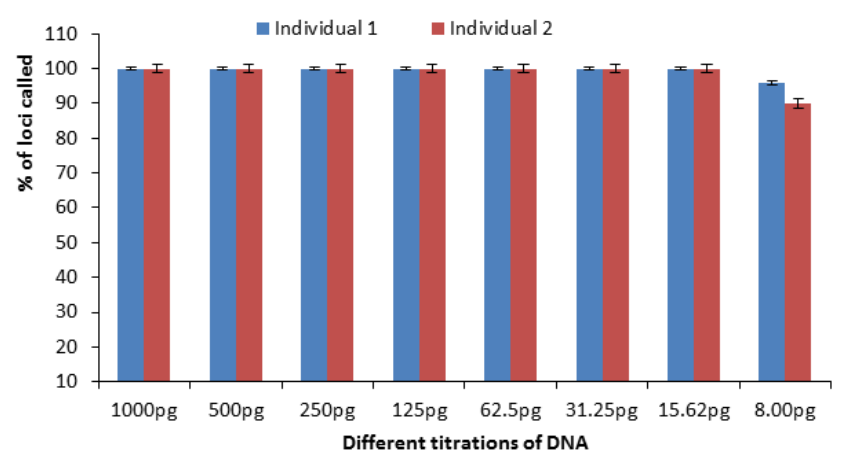

Figure 3: Titration of human male DNA. Amplification reactions containing 1000 pg, 500 pg, 250 pg, 125 pg, 62.5 pg, 31.25 pg,15.62 pg and 8.00 pg DNA were performed. The average percentage of loci called for Male 1 is represented in blue, while the average percentage of loci called for male 2 is represented in red. Error bars show the standard deviation between the four replicate amplification reactions for each concentration tested. the Genetic Analyzer 3100 (AB/LT/Thermo). GeneMapper ID v.3.2 ( $\mathrm{AB} / \mathrm{LT} /$ Thermo) was used to determine fragment size and allele calls with a 50RFU analytical threshold. Sizing precision is vital for accurate genotyping. Internal lane standard (ILS) is used in fragment analysis to ensure accurate sizing. To ensure precision with the ILS, allelic ladder were run across multiple capillaries on 3100 Genetic Analyzer.

\section{Results and Discussion}

Full Y 23 STR profile was obtained from a DNA sample as low as $15.62 \mathrm{pg}$ (Figure 3). The sensitivity study was performed to determine the optimal DNA concentration range that would yield quality profiles containing no pull-up, drop-out, off-scale peaks, any other artefacts or peak height imbalances of $<50 \%$. Data showed a DNA input range of 125 pg $-1000 \mathrm{pg}$ was optimal for half-reaction amplification protocol using the PP Y23, with best quality results at 125,200 and $250 \mathrm{pg}$. In addition half volume reactions showed high sensitivity by exhibiting great peak heights specially when working with vaginal swabs containing high female DNA quantity.

Amplifying more than $1000 \mathrm{pg}$ of DNA produced peak heights above 8000 RFU that resulted in pull-up, split peaks, increased stutters and the profile was not clean however all the alleles were called. Increasing DNA quantity resulted in poor quality profiles with peaks imbalance; partial/total reaction inhibition was observed when working with too much DNA. The sensitivity was tested with extracted DNA and $1.2 \mathrm{~mm}$ punches from either blood or buccal samples on FTA Cards. Complete profiles were obtained for all of the tested samples with either one or two $1.2 \mathrm{~mm}$ punches. Full profiles were detected in 8 of the 10 replicates in case of FTA having blood sample and 9 of the 10 replicates in case of FTA having buccal cells with $1.2 \mathrm{~mm}$ punches added to the reaction. Reduction of reaction volume to 10 and $7 \mu$ from $12.5 \mu \mathrm{l}$, showed an increase in sensitivity. All the samples tested with 200 pg DNA resulted in complete Y STR profile. The samples mixed with different concentrations of inhibitors, hematin and humic acid (up to $500 \mu \mathrm{M} / \mu \mathrm{l}$ concentration of hematin and $100 \mathrm{ng} / \mu \mathrm{l}$ concentration of humic acid), resulted into full Y-STR profile, showing the robustness of the kit and its improved tolerance for inhibitors. The above mentioned virtue of the kit proves its suitability for forensic casework samples. After this concentration of tested inhibitors, partial DNA profile was obtained. System reliability was evaluated with samples encountered in criminal cases. At the DNA fingerprinting facility of authors the PP Y23 kit was tested with all variety of forensic samples: sperm and epithelial fractions from underwear which is common in rape cases, underwear and sanitary pad of rape victim in menses, cases of rape with girl child i.e. with exhibits with excessive female bleeding, nails of female expecting to have male cells, coloured cotton clothing which leave colour in making them wet during DNA extraction, blood stained soil and a bloodstain from a bed sheet. In most of these samples only female autosomal profile could be detected (Figure 4a) with/without a small Y (Figure $4 \mathrm{~b}$ ) on amelogenin marker in very few samples with the Identifiler Plus (AB/LT/Thermo) multiplex autosomal STR kit which is very reliable kit for almost all the forensic samples for generating autosomal STR profile including samples having high inhibitor concentrations. All the samples produced a full YSTR profile with the PP Y23 System (Figure 4c) which otherwise if only tested with autosomal STR multiplex even after differential extraction would have resulted as a single source profile of female. The PP Y23 kit is by now tested on more than 500 casework samples successfully. The results from the samples in this study were consistent with the PP Y23 data generated from different samples (under garments, vaginal smear slide, pubic hair and/or mixed samples recovered from scene of occurrence) 


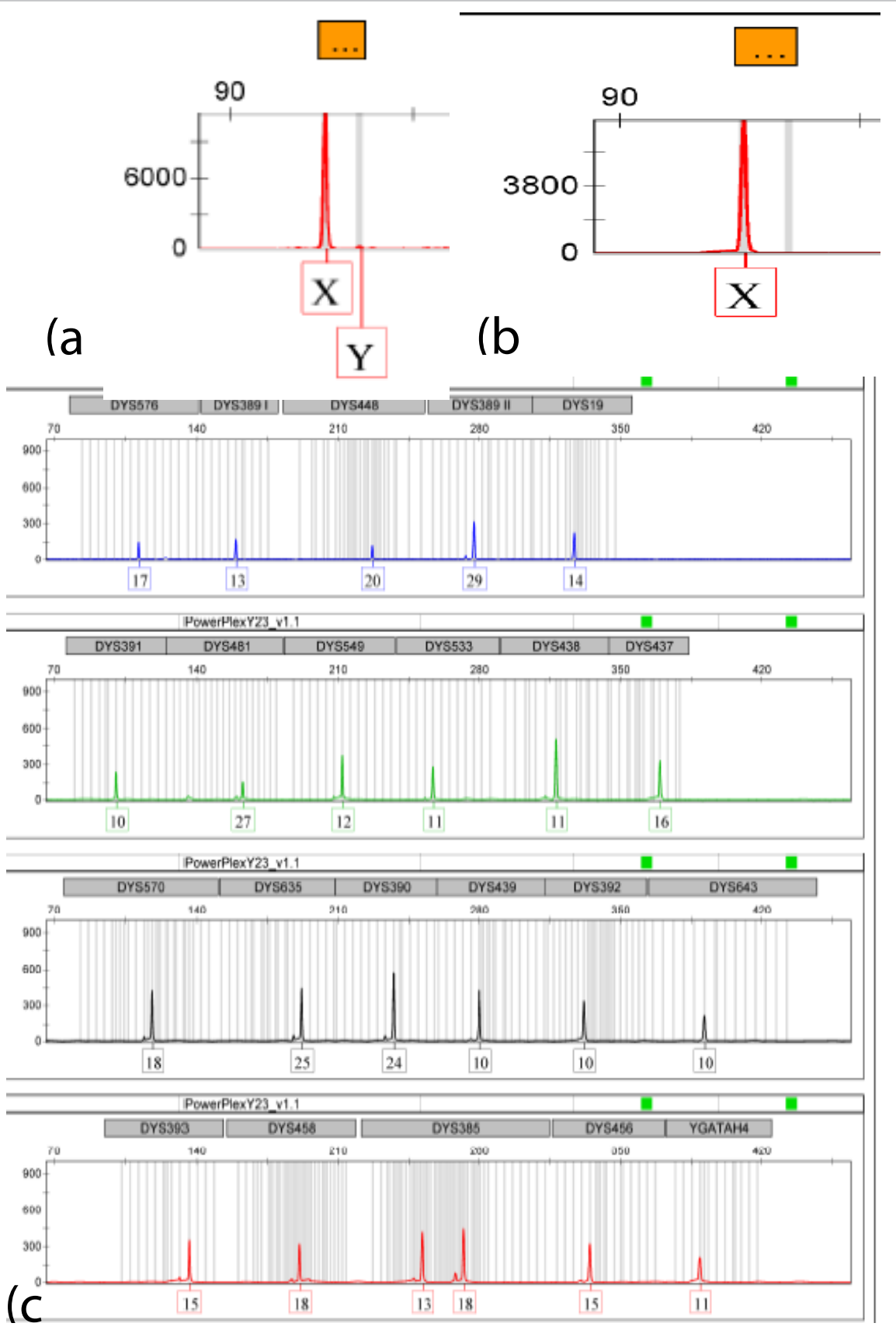

Figure 4: DNA typing of autosomal (Identifiler plus kit) and Y STR (PP Y23 system) in a real case, in autosomal STR amplification, with/without a small Y (a,b), female dominating single source profile was generated however the same sample on testing with PP Y23 gave a complete Y STR profile (c).

of the same victim. Except few split peaks, all the saliva samples were typed correctly when tested for direct PCR amplification with 13, 10 and $7 \mu \mathrm{l}$ reaction volume. Correct and complete male DNA profile was obtained from all the M:F mix, showing that the kit is quite sensitive in amplifying male DNA component. In our study the PP Y 23 system was able to generate full profiles even with the vastly masked male component in a M:F mixture sample (Figure 5).

In addition to the evaluation and validation experiments, unrelated male individuals of two different tribal populations were typed with the PP Y23 system. The data is submitted to YHRD (www.yhrd.org) population database (Table 1).
Forensic parameters (gene diversity, haplotype diversity, discrimination capacity, and match probability) were calculated and results were then compared to the values calculated for the subsets of the 16, 12 and 9 Y-STR markers. As expected, the PP Y 23 system provided a higher power of discrimination than the other three marker sets, further proving its usefulness for forensic and population genetics purposes.

During trial of PP Y23 on a wide variety of forensic samples during last one year, another very interesting observation was the finding of only one or two locus mismatch in Y23 STR profile of two unrelated individuals (Table 2). This further encompasses the possibility of false 
Citation: Jain T, Shrivastava P, Bansal DD, Dash HR, Trivedi VB (2016) PowerPlex Y23 System: A Fast, Sensitive and Reliable Y-STR Multiplex System for Forensic and Population Genetic Purpose. J Mol Biomark Diagn 7: 281. doi:10.4172/2155-9929.1000281

Page 5 of 7

inclusion as well in sexual assault case with the use of lower marker multiplex for forensic purpose.

Male DNA profiles of brothers were also consistent for all the tested samples. The analysis of studied brother pairs indicates that the PP Y 23 system can distinguish different brother pairs (Table 3).

High genetic diversity values above 0.5 for most of the loci (21) and more than 0.4 (on 2 loci) were found when the kit was used with various population samples. The multi copy locus DYS385 reached a GD value of 0.934 in the tested tribal population (Figure 6).

Summarizing the data it is concluded that, The PP Y 23 system is able to cope with very small amounts of male DNA, as well as with

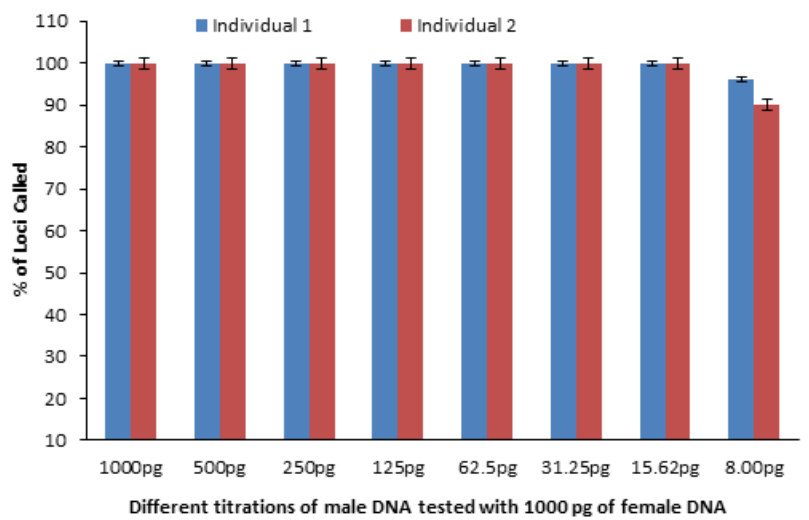

Figure 5: Amplification of $1000 \mathrm{pg}, 500 \mathrm{pg}, 250 \mathrm{pg}, 125 \mathrm{pg}, 62.5 \mathrm{pg}$, and $31.25 \mathrm{pg}, 15.62 \mathrm{pg}$ and $8.00 \mathrm{pg}$ of male DNA was performed in the presence of $1000 \mathrm{pg}$ of female DNA. The average percentage of loci called for male 1 is represented in blue, while the average percentage of loci called for male 2 is represented in red. Error bars show the standard deviation between the four replicate amplification reactions for each male with the specified DNA concentrations.

\begin{tabular}{|c|c|c|c|}
\hline $\begin{array}{c}\text { Genetic } \\
\text { Markers }\end{array}$ & $\begin{array}{c}\text { Y STR profile from the source of } \\
\text { rape victim }\end{array}$ & Suspect I & Suspect II \\
\hline DYS576 & 18 & 19 & 19 \\
\hline DYS389I & 14 & 13 & 13 \\
\hline DYS448 & 20 & 20 & 20 \\
\hline DYS389 II & 31 & 31 & 31 \\
\hline DYS19 & 16 & 15 & 15 \\
\hline DYS391 & 10 & 11 & 11 \\
\hline DYS481 & 23 & 23 & 23 \\
\hline DYS549 & 12 & 12 & 12 \\
\hline DYS533 & 12 & 12 & 12 \\
\hline DYS438 & 11 & 11 & 11 \\
\hline DYS437 & 14 & 14 & 14 \\
\hline DYS570 & 16 & 18 & 18 \\
\hline DYS635 & 23 & 23 & 23 \\
\hline DYS390 & 23 & 24 & 24 \\
\hline DYS439 & 11 & 10 & 10 \\
\hline DYS392 & 11 & 11 & 11 \\
\hline DYS643 & 10 & 10 & 10 \\
\hline DYS393 & 13 & 13 & 13 \\
\hline DYS458 & 16 & 17 & 17 \\
\hline DYS385 & 12 & 11,14 & 11,15 \\
\hline DYS456 & 14 & 15 \\
\hline YGATA4 & 12 & 12 \\
\hline
\end{tabular}

Table 2: PP Y23 STR analysis in a real case of sexual assault, which was a case of exclusion of suspects but both the unrelated suspects (from the same cast), showed only one locus difference in Y STR profile.

\begin{tabular}{|c|c|c|c|c|}
\hline \multirow{2}{*}{ Genetic Markers } & \multicolumn{3}{|c|}{$\begin{array}{c}\text { Family 1 } \\
\text { Blood relative males }\end{array}$} & \multicolumn{2}{|c|}{ Family 2 } \\
& Blood relative males \\
\hline DYS576 & 18 & I & I & I \\
\hline DYS389I & 14 & 18 & 19 & 19 \\
\hline DYS448 & 19 & 14 & 13 & 13 \\
\hline DYS389 II & 30 & 30 & 19 & 19 \\
\hline DYS19 & 15 & 15 & 16 & 30 \\
\hline DYS391 & 10 & 10 & 11 & 16 \\
\hline DYS481 & 22 & 22 & 23 & 11 \\
\hline DYS549 & 12 & 12 & 12 & 12 \\
\hline DYS533 & 13 & 13 & 11 & 11 \\
\hline DYS438 & 9 & 9 & 11 & 11 \\
\hline DYS437 & 14 & 14 & 14 & 14 \\
\hline DYS570 & 19 & 19 & 18 & 18 \\
\hline DYS635 & 21 & 21 & 23 & 23 \\
\hline DYS390 & 21 & 21 & 24 & 24 \\
\hline DYS439 & 12 & 12 & 10 & 10 \\
\hline DYS392 & 11 & 11 & 11 & 11 \\
\hline DYS643 & 9 & 9 & 10 & 10 \\
\hline DYS393 & 12 & 12 & 14 & 14 \\
\hline DYS458 & 18 & 18 & 16 & 16 \\
\hline DYS385 & 15,17 & 15,17 & 11,14 & 11,14 \\
\hline DYS456 & 16 & 16 & 16 & 16 \\
\hline YGATA4 & 11 & 11 & 12 & 12 \\
\hline & & & & 16 \\
\hline
\end{tabular}

Table 3: Y STR profile of two families using PP Y23 systems.

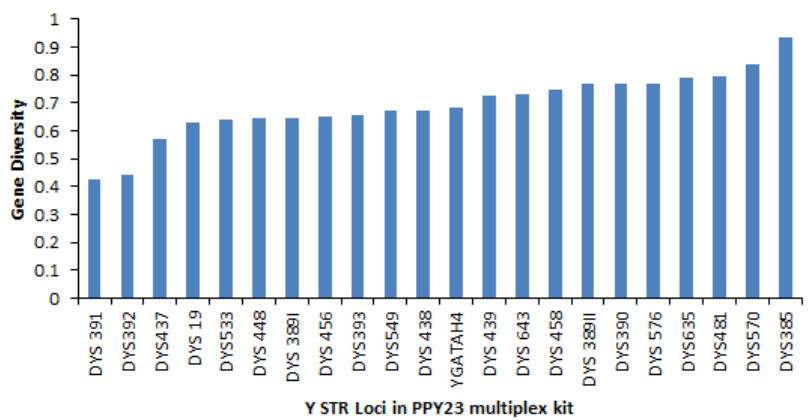

Figure 6: Locus wise gene diversity values for the 23 Y-short tandem repeat loci in a tribal population of Madhya Pradesh $(\mathrm{N}=188)$.

the common inhibitors which are often found in forensic samples. Full Y-chromosomal STR profiles could be generated even from mixtures with very low male component masked by high amount of female material, which is the common issue confronted in sexual assault cases. Failing to amplify and report the masked or trace male elements in sexual assault cases may lead to erroneous judgements. Seeing the current status of Y-STR DNA database (Tables 4 and 5), and the high potential of Y 23 markers, number of population studies is also expected to increase.

\section{Conclusion}

The PP Y23 system is able to detect even very low quantity of male DNA masked by excessive amounts of female DNA. Full profile from challenging casework samples can be generated even with high concentrations of inhibitors prevailing in the samples. It is time saving with rapid-cycling protocols. It has the potential to simplify the workflows as one kit will suffice for both casework and database samples. It works well even with the direct amplification protocol of 
Citation: Jain T, Shrivastava P, Bansal DD, Dash HR, Trivedi VB (2016) PowerPlex Y23 System: A Fast, Sensitive and Reliable Y-STR Multiplex System for Forensic and Population Genetic Purpose. J Mol Biomark Diagn 7: 281. doi:10.4172/2155-9929.1000281

Page 6 of 7

\begin{tabular}{|c|c|c|c|c|}
\hline Haplotype Format & Number of Markers & Number of haplotypes & Number of population samples & $\begin{array}{c}\text { Number of national } \\
\text { databases }\end{array}$ \\
\hline Minimal & $\mathbf{9}$ & 160,693 & 1015 & 129 \\
\hline PowerPlex Y & 12 & 121,402 & 763 & 119 \\
\hline Y filler & 17 & 109,137 & 680 & 112 \\
\hline PowerPlex Y23 & 23 & 26,869 & 190 & 58 \\
\hline Y filler plus & 26 & 8,184 & 35 & 15 \\
\hline SOurce: https://yhrd.org/pages/resources/stats\#haplotype_counts (last accessed on 13.03.16) \\
\hline
\end{tabular}

Table 4: Publically-available Y-STR database - YHRD.

\begin{tabular}{|c|c|c|}
\hline Name & Description & \multicolumn{1}{c|}{ Loci } \\
\hline Minimal & YHRD Core Loci & DYS19, DYS389I, DY389II, DYS390, DYS391, DYS392, DYS393, DYS385 \\
\hline PowerPlexY & Promega PowerPlex ${ }^{\circledR} Y$ & DYS391, DYS389I, DYS439, DYS389II, DYS438, DYS437, \\
\hline DYS19, DYS392, DYS393, DYS390, DYS385
\end{tabular}

Table 5: Description of loci in YHRD database.

saliva samples without any prior treatment and that too in half reaction volume of the recommended protocol.

\section{Acknowledgement}

Authors are thankful to the Director, State Forensic Science Laboratory, Sagar (Madhya Pradesh), India for providing laboratory facility and encouragement. Authors are also thankful to Promega, (India) for providing PP Y23 genotyping kit used in the study.

\section{Authors contributions}

PS designed the study, did genotyping of samples and contributed significantly in data analysis and drafted the manuscript. TJ helped in isolation/amplification of samples, data management, statistical analysis and drafting the manuscript. DDB, HRD and VBT did isolation/amplification/genotyping of forensic cases and helped in drafting the manuscript. All authors read and approved the final manuscript.

\section{References}

1. Pankaj S, Jain T, Trivedi VB (2016) DNA fingerprinting: A substantial and imperative aid to forensic investigation. Euro J Forensic Sci 3: 3.

2. Gill P, Jeffreys AJ, Werrett DJ (1985) Forensic application of DNA 'fingerprints'. Nature 318: 577-579.

3. Prinz M, Boll K, Baum H, Shaler B (1997) Multiplexing of $Y$ chromosome specific STRs and performance for mixed samples. Forensic Sci Int 85: 209-218.

4. Honda K, Roewer L, Knijff P de (1999) Male DNA typing from 25-year-old vaginal swabs using $Y$ chromosomal STR polymorphisms in a retrial request case. J Forensic Sci 44: 868-872.

5. Betz A, Bassler G, Dietl G, Steil X, Weyermann G, et al. (2001) DYS STR analysis with epithelial cells in a rape case. Forensic Sci Int 118: 126-130.

6. Prinz M, Sansone M (2001) Y chromosome-specific short tandem repeats in forensic casework. Croat Med J 42: 288-291.

7. Parson W, Niederstatter H, Kochl S, Steinlechner M, Berger B (2001) When autosomal short tandem repeats fail: optimized primer and reaction design for Y-chromosome short tandem repeat analysis in forensic casework. Croat Med J 42: 285-287.

8. Jobling MA, Tyler-Smith C (1995) Father and sons: the $Y$ chromosome and human evolution. Trends Genet 11: 449-456.
9. Underhill PA, Shen P, Lin AA, Jin L, Passarino G, et al. (2000) Y chromosome sequence variation and the history of human populations. Nat Genet 26: 358-361.

10. Wang CC, Li H (2013) Inferring Human History in East Asia from $Y$ Chromosomes. Investig Genet 4: 11.

11. Knijff P de (2000) Messages through bottlenecks: on the combined use of slow and fast evolving polymorphic markers on the human $\mathrm{Y}$ chromosome. Am J Hum Genet 67: 1055-1061.

12. Hammer MF, Karafet TM, Redd AJ, Jarjanazi H, Santachiara-Benerecetti S, et al. (2001) Hierarchical patterns of global human Y-chromosome diversity. Mol Biol Evol 18: 1189-1203.

13. Roewer L, Kayser M, Dieltjes P, Nagy M, Bakker E, et al. (1996) Analysis of molecular variance (AMOVA) of Y-chromosome-specific microsatellites in two closely related human populations. Hum Mol Genet 5: 1029-1033.

14. Redd AJ, Clifford SL, Stoneking M (1997) Multiplex DNA typing of shorttandemrepeat loci on the $Y$ chromosome. Biol Chem 378: 923-927.

15. Butler J, Schoske R, Vallone P, Kline M, Redd AJ, et al. (2002) A novel multiplex for simultaneous amplification of $20 \mathrm{Y}$ chromosome STR markers. Forensic Sci Int 129: 10-24.

16. Kayser M, Caglia A, Corach D, Fretwell N, Gehrig C, et al. (1997) Evaluation of Y-chromosomal STRs: a multicenter study. Int J Legal Med 110: 125-133.

17. Kayser M, Knijff P de, Dieltjes P, Krawczak M, Nagy M, et al. (1997A)Applications of microsatellite-based $\mathrm{Y}$ chromosome haplotyping. Electrophoresis 18 1602-1607.

18. Knijff P de, Kayser M, Caglia A, Corach D, Fretwell N, et al. (1997) Chromosome $\mathrm{Y}$ microsatellites: population genetic and evolutionary aspects. Int J Legal Med 110: $134-149$.

19. https://www.promega.com/ /media/files/resources/protocols/technical\%20 manuals/101/powerplex\%20y23\%20system\%20protocol.pdf

20. Thompson JM, Ewing M, Frank W, Pogemiller J, Nolde C, et al. (2013) Developmental validation of the PowerPlex Y23 System: a single multiplex YSTR analysis system for casework and database samples. Forensic Sci Int 7: 240-250.

21. Davis C, Ge J, Sprecher C, Chidambaram A, Thompson JM, et al. (2013) Prototype PowerPlex1 Y23 System: a concordance study. Forensic Sci Int 7 204-208. 
Citation: Jain T, Shrivastava P, Bansal DD, Dash HR, Trivedi VB (2016) PowerPlex Y23 System: A Fast, Sensitive and Reliable Y-STR Multiplex System for Forensic and Population Genetic Purpose. J Mol Biomark Diagn 7: 281. doi:10.4172/2155-9929.1000281

22. Barbaro A, Cormaci P (2015) Validation of PowerPlex Y23 System (promega) using reduced reaction volume. Forensic Science International: Genetics Supplement Series 5: e373-e374.

23. Pascali VL, Dobosz M, Brinkmann B (1999) Coordinating Y-chromosomal STR research for the Courts. Int J Legal Med 112: 1

24. Swgdam, Y (2007) Report on the current activities of the scientific working group on DNA analysis methods Y-STR subcommittee. Forensic Science Communications 6: 1-2.
25. Roewer L, Krawczak M, Willuweit S, Nagy M, Alves C, et al. (2001) Online reference database of European Y-chromosomal short tandem repeat STR haplotypes. Forensic Sci Int 118: 106-113.

26. Kayser M, Kittler R, Erler A, Hedman M, Lee AC, et al. (2004) A comprehensive survey of human Y-chromosomal microsatellites. Am J Hum Genet 74: 1183-1197.

27. D'Amato ME, Ehrenreich L, Cloete K, Benjeddou M, Davison S (2010) Characterization of the highly discriminatory loci DYS449, DYS481, DYS518, DYS612, DYS626, DYS644 and DYS710. Forensic Sci Int Genet 4: 104-110. 